\title{
Erratum
}

Leptin-dependent neuronal NO signaling in the preoptic hypothalamus facilitates reproduction

Nicole Bellefontaine, Konstantina Chachlaki, Jyoti Parkash, Charlotte Vanacker, William Colledge, Xavier d'Anglemont de Tassigny, John Garthwaite, Sebastien G. Bouret, and Vincent Prevot

Original citation: J Clin Invest. 2014;124(6):2550-2559. doi:10.1172/JCI65928.

Citation for this erratum: J Clin Invest. 2014;124(8):3678. doi:10.1172/JCI77652.

During the preparation of this manuscript, incorrect units were entered for the $y$ axis label of Figure 6C. The correct figure part is below.

The JCI regrets the error.

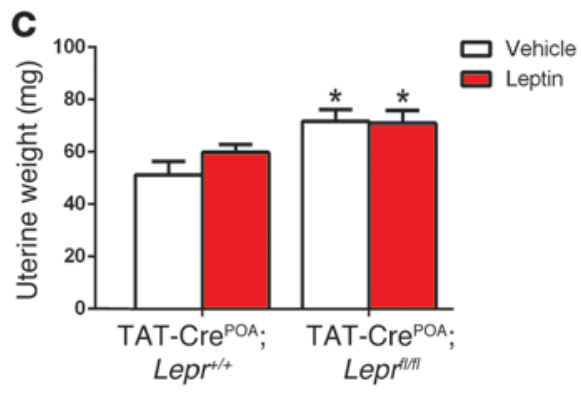

\section{Clinical Research Scholar} Career Development Training Opportunity

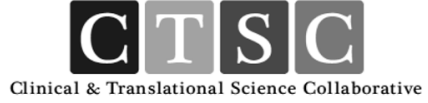

The CTSC KL2 seeks outstanding candidates to fill Clinical Research (CR) Scholar positions available in July 2015. The training program is a component of the Cleveland CTSC and is funded by the NIH. CR Scholars will embark on a

4-year program of intensive training in interdisciplinary team-based, patient-oriented research, combining a novel educational program with mentored research experiences.

Qualified candidates

- Hold an M.D., a Ph.D., a D.D.S., a Pharm.D., a Psy.D. or a equivalent degree

- Have demonstrated a keen interest in clinical research - Have expertise relevant to clinical research

- Have an appointment in one of the Departments in the University or medical centers

-Are U.S. citizens or have permanent resident status

Successful candidates will receive a CWRU appointment, with salary and benefits commensurate with prior experience and qualifications, research stipend, tuition benefits, and access to a multidisciplinary pool of highly qualified mentors who will guide their research projects.

Interested applicants should contact Beth Spyke, MPA, for information and application instructions at:

spykeb@ccf.org: 216-444-2702 or visit:

$\mathrm{http}: / /$ casemed.case.edu/ctsc/education/k12/.
WV/ SCHOOL OF MEDICINE

Cleveland Clinic

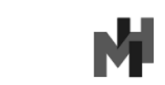

MetroHealth
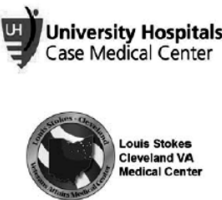

Applications will be accepted between $7 / 1 / 14-10 / 27 / 14$
For more information about the CTSC visit

http://casemed.case.edu/ctsc/.

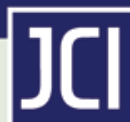

High-profile publications in:

Clinical Medicine

Melanoma immunotherapy using mature DCs expressing the constitutive proteasome

jci.org/articles/view/67544

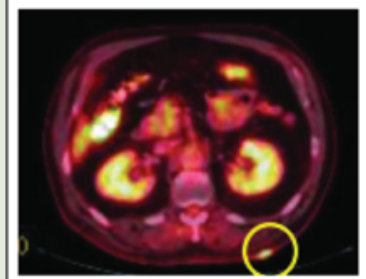

Prevaccination

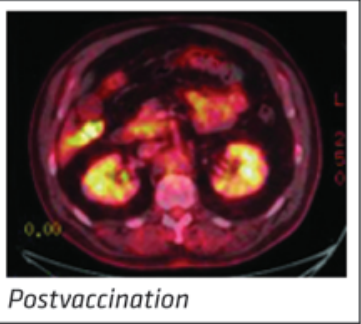

Metabolic response to sodium-glucose cotransporter 2 inhibition in type 2 diabetic patients jci.org/articles/view/72227

Essential amino acid supplementation in patients following total knee arthroplasty

jci.org/articles/view/70160 